\title{
Vegetation and Soil Properties Recovery, Biomass Accumulation after Limestone Quarry Restoration
}

\author{
Denis U. Austin* \\ Viikki Tropical Resources Institute (VITRI), Department of Forest Science, Faculty of Agriculture and \\ Forestry, University of Helsinki.
}

* Corresponding author. Tel.: +35845096226; email: e-mail: denis.austin@helsinki.fi

Manuscript submitted May 30, 2016; accepted October 25, 2016.

doi: 10.17706/ijbbb.2017.7.1.58-65

\begin{abstract}
The rehabilitation of exhausted quarries through nurse plants-led afforestation is widespread and growing in importance in many parts of the Tropics. The long-term recovery of native plant species and soil organic properties under the approach has, however, not well understood. The number of studies so far to examine soil and vegetation change in restored quarries have been mostly constrained to land mined of coal or bauxite, and post-restoration treatment time not more than 25 years. This short timeframe can only capture the colonization span of pioneer species and not those of intermediate and late successional trees and shrubs. The purpose of the study is to determine how three commonly utilized nurse-tree species (Albizia lebbek, Casuarina equisetifolia and Eucalyptus camadulensis) associate with late succession native species, estimate aboveground biomass accumulation under their respective stands, and to examine soil organic properties development under their pure plantations. The study will be conducted in limestone mining areas of coastal Kenya where quarry rehabilitation has been on-going for a continuous period of 46 years. The split plot design will be used to demarcate study plots in the area according to nurse-tree used and age of restoration planting. One month after the bimodal rainfall seasons (July 2016 \& January 2017) in Kenya, independent field samplings will be conducted to determine native species richness and relative abundance in each plot type. A different set of field studies will be carried out in to investigate how the diversity of native plant communities, the soil seed bank and organic matters change with time since restoration treatment ( 5 - 45 yrs) under the different nurse-tree species. Soil seed bank determination will be carried out through glasshouse seedling germination method and tetrazolium separation test. Soil organic matter determination will be done through hydrogen peroxide digestion experiment. Net primary production in the experimental plots will be calculated using the Forest-BCG model, while the Pipe model will be employed to estimate growth allocation to the aboveground state variables.
\end{abstract}

Key words: Nurse-plants, quarry, restoration, seed bank, vegetation recovery.

\section{Introduction}

The recovery of vegetation in areas rehabilitated after mining degradation has generated research interest over the last two decades. Despite that, there is still a little understanding of long-term changes in vegetation and soil properties in areas restored after quarrying of limestone and other minerals. In such restoration projects, a key target is usually the re-establishment of plant community that can reproduce itself indefinitely with little or no further human intervention. Restoring limestone quarries to this functional state is difficult to achieve due to the coarse nature of mined surfaces, which in some cases 
contain foreign residues from industrial extraction processes like in those involving the use of ammonium nitrate and fuel oil explosives [1]. One method to overcome this difficulty is by the use of nurse tree-led afforestation to first stabilize the terrain, accelerate soil formation and provide suitable conditions for subsequent establishment of other plant species, especially native colonizers. Nurse-trees are usually fast-growth exotic species that can withstand the sometimes hostile environments of quarried areas normally characterized by low soil content and scarcity of nutrients. In many parts of the tropic, commonly adopted nurse-tree species include Casuarina equisetifolia, Albizia lebbek and Eucalyptus sp. Despite the success of these plants in land rehabilitation, little is known about how they individually associate with late successional native species. Net primary production (NPP) under pure stands of the Albezia lebbek, Casuarina equistefolia, or Eucalyptus camadulensis has also not been assessed for regional reference and to the species-specific biomass equation.

In general, vegetation succession after large scale disturbance has generated research attention for a longer time. The classical ecological understanding isthat the initial floristic composition (IFC) after disturbance is the principle determinant of future vegetation [2], [3]. Several changes in the IFC will occur and progressively give way to successors until an enduring community finally develops to perpetuate itself. A number of restoration success assessments have been conducted around the world evaluated the extents of native plants community re-establishment following quarry reclamation treatments. Some of the findings were indicative of successional shift of community in the direction of the pre-mining conditions [4], while other results were contrary to established ecological understanding. In south western Virginia for example, although the research by [5] recorded increases in pioneer native species in nurse-trees reclaimed coal mines, the study did not report a corresponding increase in intermediate and late succession trees or shrubs species in same area. Similar conflicting findings were reported by [6] and [7].

One limitation, however, is that most of these recent studies were conducted in bauxite and coal quarry rehabilitation sites that are normally hostile to the re-establishment success of a variety of species. Residual heavy metals on such sites can reduce beneficial basal elements and produce low calcium-magnesium ratios, which hinder nitrogen assimilation and therefore the re-establishment of many target species [8], [9]. Findings from such sites can therefore not be generalized to limestone quarry restoration areas where, on the contrary, presence of calcium-rich residues favor the establishment of a diversity of plants, including calcareous grasses, shrubs and trees. Moreover, a majority of the past studies have been constrained to about 25or less years since restoration treatments. Restoration assessment at that timeframe can only enable the observation of dynamics within the pioneer nurse-trees and other early succession species. In tropical, sub-tropical and Mediterranean climates where colonization by intermediate and late successional species normally begins around 26 - 30 years, older restoration sites will need to be examine to understand long-term soil and vegetation change, and that is even assuming that the right biophysical conditions are in place. In quarry restoration sites characterized by nutrient deficient, coarse surfaces, the return of native plant species and formation of propagule-rich topsoil constitute quasi recovery indicators. Their establishment is crucial in the effort to re-establish and perpetuate a self-sustaining, stable community similar to the pre-disturbance vegetation, the essence of ecological restoration [10], [11].

The study has four objectives. 1) To examine how each of the common nurse-tree species (Albezia lebbek, Casuarina equistefolia, Eucalyptus camadulensis) associate with native plant species at different stages (2 to 45 years) after their use in quarry rehabilitation treatment. 2) To assess the NPP between pure plantation forests of Albezia lebbek, Casuarina equistefolia, Eucalyptus camadulensis and the adjacent areas with natural vegetation. 3) To evaluate and compare soil seed bank, soil depth and soil organic matter accumulation under the different nurse-plants. 4) To compare species richness and evenness between plots of different rehabilitation ages 2 - 45 years after quarry restoration, irrespective of treatment type. 
Independent field measurements, glasshouse and laboratory experiments will be conducted over a period of two years in restored limestone quarries to test the null hypotheses: i) there are no differences in species composition around the basal areas of Albezia, Casuarina and Eucalyptus species in the rehabilitated limestone quarries and the adjacent unmined sites, ii) there is no difference in NPP between stands of Albezia lebbek, Casuarina equistefolia, Eucalyptus camadulensis forests and the reference natural habitats in coastal Kenya, iii) the soil depth, seed bank composition and species diversity do not vary between Albezia lebbek, Casaurina equisetifolia and Eucalyptus-led nurse tree treatment plots, iv) there is no change in species richness and evenness in all the rehabilitated quarries between the ages 5, 10, 15, 20, 25 years, and older since restoration treatment (regardless of rehabilitation method).

Limestone quarrying is carried out in all regions of the world [12]. Nearly half the states of Africa have commercial scale deposits of the mineral. Industrial quarrying of limestone for cement is done in at least 15 countries of the continent, and many more are attracting investments. Africa received $15 \%$ of the global foreign direct investments in the mining sector in 2014. The Dangote Group has unveiled a plan to invest S5 billion on limestone reserves across the continent to meet the rising demands for cement, fertilizers and plastic processing carbonates. The building sector in Kenya alone consumes 5 million tonnes of cement produced in that country in 2015, up from 2.8 million in 2008 [13]. These figures translate to thousands of hectares already quarried and needing to be reclaimed. With the entry of the Chinese mining companies with billions of dollar investments in the coal and limestone sectors, a further area measuring 180 square kilometers is set to be quarried in the coming years in one country alone. Areas of coastal Kenyan already quarried of limestone and at various stages of rehabilitation provide excellent opportunity to examine medium and long-term vegetation change after nurse-plant treatment. This afforestation-led approach to restoration has gone on in the region on a continuous basis for more than 45 years. The availability of rehabilitated plots at different ages of establishment and maturity will enable a field observation of chronosequence changes in vegetation following nurse tree-led afforestation treatments for land rehabilitation

\section{Site Description}

The study will be conducted in limestone mining areas along the Kenyan coast $\left(39^{\circ} .43^{\prime} \mathrm{E}\right.$ and $\left.4^{\circ} 00^{\prime} \mathrm{S}\right)$. The area stands at about $60 \mathrm{~m}$ above sea level and receives average annual rainfall of $1144.3 \mathrm{~mm}$ which mostly occur in bimodal seasons (April - June \& October - November). With a mean daily temperature of $26^{\circ} \mathrm{C}$, the region is a tropical wet and dry climate according to the Koppen classification system. The vegetation is characterized by Miombo savanna bushland, with wide distribution of indigenized palm tree species. The study sites are all located in mining concession lands belonging to the Lafarge Group. These include the Haller Park, Mombasa and other limestone quarry rehabilitation sites at Vipingo and Diani, Kwale County.

The Haller Park (formerly known as Bamburi Nature Trail) is a globally unique sites. Restoration work began there in 1971 to reclaim disused mines, which prior to the time constituted unintended wetlands, environmental hazard and an eyesore. The nature trail is among the few conservancies around the world successfully reclaimed after large scale industrial mining for limestone. In the other experimental sites, restoration methods vary from the nurse tree planting to other approaches, with age of rehabilitation treatment ranging 2 - 30 years. Together, the experimental sites will enable a comparative study of vegetation change after limestone quarry restoration, both along a chronosequence of 2 to 45 years and across restoration types.

\section{Experimental Plots Design}

Restoration plantings at 2 - 20-year old plots in the study sites were systematically done annually and 
block-wise at the study sites, with each plot planted with a single type of nurse-tree species. In a few of these plots as in those older than 25 years, mixed planting of the species were carried out. In some areas, the mono-cropping of the species was done in not-yet-quarried limestone reserve lands using similar, systematic annual and block planting approach. As shown in Fig.1, the slip plot design already follows this systematic pattern.

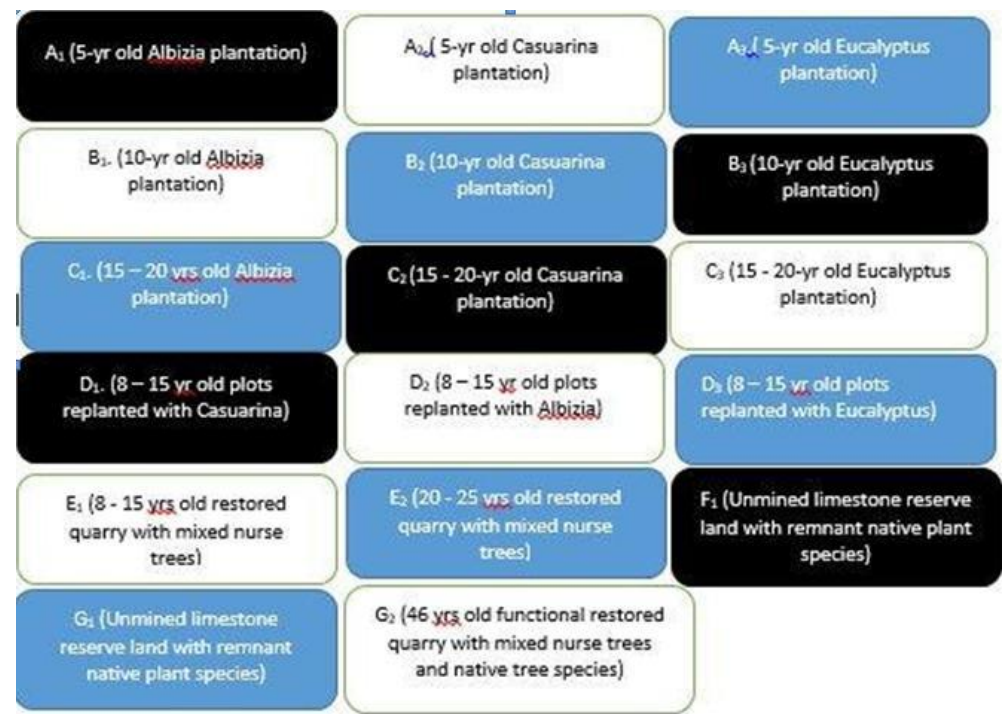

Fig. 1. Split plot design of the experimental blocks following the patterns of nurse-tree planting and stand ages.

The younger experimental sites contain mono-crop stands of Albizia lebbek, Casuarina equistefolia and Eucalyptus camadulensis species planted in exhausted quarries on an annual sequence between 2 to 20 years ago. In Fig.1, stands of each of the three species 5 years or younger are designated $A_{1}, A_{2}$ and $A_{3}$ respectively. 10-yr old stands of the same species are designated B1, B2 and B3 respectively. Stands of the respective species aged $15-20$ years are labeled $\mathrm{C}_{1}, \mathrm{C}_{2}$ and $\mathrm{C}_{3}$. The $\mathrm{D}_{1}, \mathrm{D}_{2}$ and $\mathrm{D}_{3}$ plots are stands of the same nurse-tree species (Albizia lebbek, Casuarina equisetifolia and Eucalyptus camadulensis) respectively, planted in yet-to-be quarried limestone reserved lands whose natural vegetation has been removed. Ages since rehabilitation planting on these sites range between 8 and 15 years. Plot E1and E2 are on similar lands as $D_{1}-D_{3}$, but with mixed plantings of the nurse-tree species at different ages of maturity. Plot $\mathrm{G}_{2}$ represents the Haller Park where restoration work began 46 years ago. 129 species were planted at this site in 1971 for rehabilitation trial, but only Casuarina lebbek, and later Albizia lebbek were successful as nurse-plants. $\mathrm{F}_{1}$ and $\mathrm{G}_{1}$ are the adjacent, un-mined limestone reserve lands with remnant native vegetation. Vegetation and soil characteristics of $\mathrm{F}_{1}$ and G1will provide the study baseline.

\section{Method}

Field measurements will be carried out to determine the basal area association of the three different nurse-tree species (Albizia lebbek, Casuarina equisetifolia, Eucalyptus camadulensis) with non-planted species. Sampling and evaluation of the species will be done one at a time in an alphabetical order, starting with Albizia sp and finishing with Eucalyptus sp. A 1.5-kilometer diagonal transects will be set across each of the homogeneous experimental blocks A1-D3 (12 blocks) in north-east orientations. Along each transect, point centered quadrats (PCQs) will be marked at $40 \mathrm{~m}$ intervals per block. The experimental tree occurring 
most proximate to each PCQ point will be selected, its diameter at breast height measured and recorded. Plant species sampling will be done at two strata: trees and shrubs ( $0.75 \mathrm{~m}$ and above), and herbs (below $0,75 \mathrm{~m}$ ). The individual numbers and the species of non-planted trees and shrubs occurring within $4 \mathrm{~m}$ in all cardinal directions of the reference nurse-tree's basal area will be recorded. Two $1 \mathrm{~m}^{2}$ quadrats will be placed at $2 \mathrm{~m}$ spatial proximity east and west of the experimental tree. Herbaceous species found in the quadrats will be identified and their individual numbers recorded. Similar transects will be set at two different instances in E1and E2heterogeneous plots planted with a mixture of the three nurse-tree species (plantings of Albizia lebbek, Casuarina equisetifolia and Eucalyptus camadulensis). Sampling will also be done at 40 m PCQ intervals, using similar technique as in A1 - D3. Vegetation sampling in plot G2will be similar to those for E1and E2.Atthe un-mined reference sites, vegetation sampling will be done at a similar PCQ intervals as in all the others. However, as planting was not done on these sites, every species will be treated equal. All trees, shrubs occurring $1 \mathrm{~m}$ from the PCQ points will be sampled. Herbaceous species will be sampled using two quadrats placed $1 \mathrm{~m}$ east and west of the PCQ points. A different transect will be set in south-west orientation in each of all the plot type. A different set of PCQs will be set across all plot types for soil sampling at $50 \mathrm{~m}$ intervals. At each point, soil depth will be determined by digging through the profile and recording the distance from zero to the core. The average soil depth for each plot type will be recorded (in centimeters) as the aggregate soil depth divided by the number of PCQs for that block. In the 5 -yr old plots, soil depth can be expected to very shallow and a value of zero may be recorded, depending on local rates of sedimentation from the upper catchments. Topsoil samples will be collected by the same PCQ points by hammering in a metal template measuring $5 \times 5 \times 5$ (depth, width, length) flat to the ground and digging out the content into a collection plate. Samples from the individual measurements will the put together and thoroughly mixed to produce a composite sample for each plot type. The composite sample will then be taken to a suitable holding place for stored at $4^{\circ} \mathrm{C}$, to minimize organic loses through microbial degradation or oxidation. Samples will later be transported to a sterile glasshouse for seedling germination experiment and laboratory analysis of

total organic carbon composition (TOC). The seed bank determination test will involve a combination of three techniques: elutriation (washing), tetrazolium separation as carried out by [14], and seedling germination. The first two methods are suitable for quick estimation, but they have a higher likelihood of missing, cryptically colored seeds. The seedling germination method can provide a better estimate of density, diversity and viability of seeds. However, it requires more time, particularly given the differences in seed germination requirements of different species. Taxonomic identification of all plants and seeds using references available at the herbariums of the National Museum of Kenya and the University of Nairobi, with the help of taxonomists from these institutions. This will be done to supplement local knowledge of the species, where available. All the field measurements will be carried out 1-2 months after the short rainfall season (October - November), and repeated 1-2 months after the long rainfall season (April - June).

\section{Models}

Although it has been demonstrated by studies that the diameter at breast height (DBH) is normally the primary predictor of aboveground biomass, auxiliary data on LAI also serves as key parameter for the same estimation using a number of models [15], [16]. Such models are easier because Lidar and remotely sensed image from satellite platforms for most regions are readily available, and have been demonstrated as effective in estimating canopy heights and leaf area index (LAI). For the study area, remote sensing data will be procured through the Regional Center for Mapping of Resources for Development (RCRMD) Kenya. Simulation of annual change in NPP at the reference sites will be done using the FOREST-BCG model [17], 
which uses the LAI as the primary input. The model has been successfully used to simulate carbon balance and forest growth based on plant physiology axioms. It calculates growth as net photosynthate $\left(\mathrm{G}_{\mathrm{L}}\right)$ minus loss by respiration and senescence, with $\mathrm{G}_{\mathrm{L}}$ depending on insolation and LAI. The model assumes a scenario of nitrogen $(\mathrm{N})$ being the limiting factor in cases where carbon is in adequate supply. For the case of the study site, $\mathrm{N}$ will be substituted by phosphorous (P), assuming that $\mathrm{N}$ is in adequate supply given the $\mathrm{N}$-fixing potential of some of the nurse trees and native colonizers. The model equation notations are as follows:

- $\mathrm{L}^{*}=$ Leaf area index (LAI)

- $\mathrm{C}_{\mathrm{LC}}=\mathrm{C}$ available for growth when $\mathrm{P} \& \mathrm{H}_{2} 0$ are non-limiting factors

- $\mathrm{R}_{\mathrm{L} / \mathrm{R}}=$ Leaf : root allocation ratios

- $\mathrm{C}_{\mathrm{L} W}=\mathrm{C}$ available for leaf growth under $\mathrm{H}_{2} \mathrm{O}$ stress

- $\mathrm{C}_{\mathrm{LP}}=\mathrm{C}$ available for leaf growth where $\mathrm{P}$ is deficient

- $\mathrm{C}_{(\mathrm{L} / \mathrm{R})}=$ Absolute carbon allocation to leaves or roots

- $\mathrm{T}_{\mathrm{s}}=$ Rooting zone fractional annual soil temperature

- $\mathrm{W}_{\mathrm{s}}=$ Average annual soil moisture fraction of field soil holding capacity

- $\mathrm{K}_{\mathrm{LTP}}=$ Litter $\mathrm{P}$ mineralization rate $\mathrm{kg} \mathrm{yr}^{-1}$

- $\mathrm{K}_{\mathrm{LTC}}=$ Annual rate of leaf/root litter decomposition

- $\mathrm{P}_{\mathrm{LT}}=$ Litter P compartment (kg/ha)

- Using the above notations, the key model structure equations can be stated as

$$
L^{*}=\mathrm{C}_{\mathrm{L}} \mathrm{SLA}
$$

where SLA is the externally determined variable denoting specific leaf area $\left(\mathrm{m}^{2} \mathrm{~kg}^{-1} \mathrm{C}\right)$

$$
\begin{aligned}
\mathrm{C}_{\mathrm{LC}} & =\mathrm{G}_{\mathrm{L}} \mathrm{R}_{\mathrm{L} / \mathrm{R}} \\
\mathrm{K}_{\mathrm{LTP}} & =\mathrm{N}_{\mathrm{LT}} œ \mathrm{~K}_{\mathrm{LTC}}
\end{aligned}
$$

$\mathrm{K}_{\mathrm{LTP} / \mathrm{N}}$ is the $\mathrm{P}$ or $\mathrm{N}$ mineralization rate, $\mathrm{kg}$ per year (œ is universal).

\section{Data Analysis}

The field measurements will provide data for the analyses of 1) native species diversity and abundance 2) diversity of functional groups among the native plant species 3) soil seed bank composition 4) soil accumulation 5) soil organic carbon composition. Native species survival around each of the nurse trees will be analyzed and compared using contingency tests (Zar 1996) [18]. Relative abundance of species will be calculated using diversity indices. The indices will be related in terms of determining and comparing the temporal effect of Albizia lebbek, Casuarina equisetifolia and Eucalyptus camadulensis on early and intermediate successional native species. Trends in individual native species dominance in the interaction with the nurse trees will be explored by intra-site ordinations by detrended correspondence analysis, using PC Ord as explained by [18]. Cumulative species diversity and abundance, seed bank composition, soil depth and soil organic matter accumulation will be analyzed using multivariate contingency tests, with the factors of nurse-tree type and age of site. These will be explored further through linearity of redundancy analysis as done by [19].

\section{Results}

Model simulation of the aboveground biomass will be calculated and published as part of the results to be presented at the ICBEM conference in September 2016.

\section{Discussion}




\section{Acknowledgment}

D. U. Austin thanks the Mikko Kaloinen Foundation for the grant, which has partly made this study possible.

\section{References}

[1] Wheater, C. P., \& Cullen, W. R. (1997). The flora and invertebrate fauna of abandoned limestone quarries in derbyshire, United Kingdome. Restoration Ecology, 5(1), 77-84.

[2] Egler, F. E. (1954). Vegetation science concept: initial floristic composition, a factor in old-field vegetation development. Vegetatio. 4, 412-417.

[3] Hobbs, R. J. (2004). Setting effective and realistic restoration goals: Key directions for research. Restoration Ecology, 15(2), 354-357.

[4] Norman, M. A., et al. (2006). Vegetation succession after bauxite mining in western Australia. Ecological Restoration, 14(2), 278-288.

[5] Holl, D. K. (2002). Long-term vegetation recovery on reclaimed coal mines in the eastern USA. Journal of Applied Ecology, 39, 960-970.

[6] Baasc, A., et al. (2012). Nine years of vegetation development in a postmining site: Effects of spontaneous and spontaneous and assisted site recovery. Journal of Applied Ecology, 49, 251-260.

[7] Hendrychova, M., et al. (2012). Soil properties and species richness of invertebrates on afforested sites after brown coal mining. Restoration Ecology, 20(5), 561-567.

[8] Bending, N. A. D., \& Moffat, A. J. (1999). Tree performance on minespoils in South Wales cornfield. Journal of Applied Ecology, 36, 784-797.

[9] Tropek, R., et al. (2010). Spontaneous limestone quarries as an effective restoration tool for endangered arthropods and plants. Journal of Applied Ecology, 47, 139-147.

[10] Bradshaw, A. D. (2002). Handbook of ecological restoration. Ecological Principles, 1. Cambridge University Press

[11] Society for Ecological Restoration International. (2006). Foundations of Restoration Ecology. Washington; Island Press.

[12] Clemente, A. S., et al. (2004). Restoration of limestone quarry: Effect of soil amendments on the establishment of native Mediterranean Sclerophyllous shrubs. Ecological Restoration, 12(1), 20-28.

[13] Government of Kenya. (2015). Economic Survey 2015. Kenya National Bureau of Statistics.

[14] Conn, J. S. (2006). Weed seed bank affected by tillage intensity for barley in Alaska. Soil \& Tillage Research, 90, 156-161.

[15] Lefsky, M. A., et al. (2005). Estimates of forest canopy height and above ground biomass using ICESat. Geophysical Research Letters, 32, L22S02.

[16] Boudreau, J., et al. (2008). Regional aboveground forest biomass using airbone and spaceborne LiDAR in Quebec. Remote Sensing Environment, 112, 3876-3890.

[17] Zhao, Q., et al. (2010). Nitrogen and phosphorus transformations in rhizospheres of three tree species in a nutrient-poor sandy soil. Applied Soil Ecology, 46, 341-3476.

[18] McCune, B., \& Mefford, M. J. (1999). Multivariate analysis of ecological data: version 4, MjM software. Glenedon Beach, Oregon. 11-28.

[19] Ghorbani, J., et al. (2007). Temporal Responses of propagule banks during ecological restoration in the United Kingdom. Restoration Ecology, 15(1), 103-117.

Denis Austin was born in Tema, Ghana in 1970. He studied geography at the University of Nairobi and completed the master of arts degree in biodiversity and natural resources management at the same university in 2012. He is now finalizing his doctor of science degree at the University of Helsinki. 
He lives and works in Helsinki, Finland as a fundraising coordinator for an international charity organization. His recent publications include: 1) Austin, U. Denis. \& Gichuki, N. (2013). Effects of legume-based rotational cropping on rhizobia assemblages in an irrigated rangeland, Southern Kenya. The International Journal of Environmental Sustainability, 8(3), 95-105. 2) Austin, U. Denis \& Gichuki, N. (2012). Challenges and possibilities of developing ecologically conscious technologies in Africa. Hekima Review (Justice \& Peace), 46(1), 102-110. 